\title{
Inhibitor protection of copper in citric acid solutions
}

\author{
Ya.G. Avdeev, ${ }^{1}{ }^{10} *$ K.L. Anfilov, ${ }^{2}$ E.P. Rukhlenko ${ }^{2}$ and Yu.I. Kuznetsov ${ }^{1}\left[{ }^{1}\right.$ \\ ${ }^{1}$ A.N. Frumkin Institute of Physical Chemistry and Electrochemistry, Russian Academy \\ of Sciences, Leninskii pr. 31, 119071 Moscow, Russian Federation \\ ${ }^{2}$ Bauman Moscow State Technical University (Kaluga Branch), Bazhenov str. 2, 248000 \\ Kaluga, Russian Federation \\ *E-mail: avdeevavdeev@mail.ru
}

\begin{abstract}
The kinetics of copper corrosion and the effect of convection on this process were studied in freely aerated citric acid $\left(\mathrm{C}_{6} \mathrm{H}_{8} \mathrm{O}_{7}\right)$ solutions. The copper corrosion rate in this medium does not depend significantly on the duration of contact between copper and the corrosive medium (1-20 days) and $\mathrm{C}_{6} \mathrm{H}_{8} \mathrm{O}_{7}$ concentration $(0.001-2 \mathrm{M})$. The corrosivity of this medium towards copper increases with the transition from static to dynamic conditions of the experiment. Also, the corrosivity of $\mathrm{C}_{6} \mathrm{H}_{8} \mathrm{O}_{7}$ solutions toward metallic copper is enhanced in the presence of the corrosion product, $\mathrm{Cu}$ (II) cations. This effect is especially pronounced when it comes into contact with a dynamic corrosive medium. A triazole derivative, IFKhAN-92, is recommended for copper protection in freely aerated $\mathrm{C}_{6} \mathrm{H}_{8} \mathrm{O}_{7}$ solutions. The efficiency of this compound does not depend considerably on the duration of contact between the metal and the corrosive medium, $\mathrm{C}_{6} \mathrm{H}_{8} \mathrm{O}_{7}$ content, and hydrodynamic characteristics of the solution. An important feature of the IFKhAN-92 inhibitor is that its protective ability toward metallic copper is preserved even if $\mathrm{Cu}$ (II) cations are accumulated in the corrosive medium, which is true not only in static but also in dynamic media. The dependence of the copper corrosion rate on the convective factor in freely aerated solution $2 \mathrm{M} \mathrm{C}_{6} \mathrm{H}_{8} \mathrm{O}_{7}+0.05 \mathrm{M} \mathrm{Cu}(\mathrm{II})$, both in the absence and in the presence of the corrosion inhibitor, is formally described by the equation $k=a+b \cdot n^{1 / 2}$, where $a$ and $b$ are empirical parameters and $n$ is the rotation frequency of the magnetic stirrer. The addition of IFKhAN-92 decreases the parameters $a$ and $b$ in this equation.
\end{abstract}

Keywords: corrosion, corrosion inhibitors, copper, citric acid, copper(II) cations, triazole.

Received: June 23, 2021. Published: July 12, 2021

doi: $\underline{10.17675 / 2305-6894-2021-10-3-5}$

\section{Introduction}

Citric acid solutions, alongside with hydrochloric and sulfuric acid solutions, are process liquids for removal of mineral impurities and corrosion products from metal surfaces [1]. An advantage of citric acid $\left(\mathrm{C}_{6} \mathrm{H}_{8} \mathrm{O}_{7}\right)$ in comparison to $\mathrm{HCl}$ and $\mathrm{H}_{2} \mathrm{SO}_{4}$ is that its corrosivity toward the most important engineering materials, such as steels, is low. This allows using them in industry, as opposed to inorganic acids, without additional inhibitor protection [2]. Technological equipment that often contacts acidic solutions is partly or wholly made of copper or its alloys. The corrosion stability of copper in $\mathrm{HCl}$ and $\mathrm{H}_{2} \mathrm{SO}_{4}$ solutions and the 
possibility of its inhibitor protection in these media are widely discussed [3-15]. Triazole derivatives are often used to protect copper in acid solutions [16-25]. In contrast, the stability of copper in $\mathrm{C}_{6} \mathrm{H}_{8} \mathrm{O}_{7}$ solutions and the possible ways of its corrosion protection are insufficiently covered in the available literature [26-29]. Our earlier studies on the corrosion ability of low carbon steel in $\mathrm{C}_{6} \mathrm{H}_{8} \mathrm{O}_{7}$ solutions showed the possibility of its efficient protection in this medium by formulations based on a triazole derivative, the IFKhAN-92 inhibitor [30]. IFKhAN-92 is an effective inhibitor of copper corrosion in acetic acid solutions [31]. The result obtained allows one to hope that efficient protection of copper in $\mathrm{C}_{6} \mathrm{H}_{8} \mathrm{O}_{7}$ solutions by this inhibitor is possible.

It should be noted that no direct reaction is possible between metallic copper and acetic acid. Copper corrosion occurs only in the presence of atmospheric oxygen in the corrosive medium that acts as its oxidant. It is reasonable to assume a multistage mechanism of this corrosion process. It is important to point out that the final corrosion product, $\mathrm{Cu}$ (II) cations, are also involved in metal corrosion. As $\mathrm{Cu}$ (II) cations are accumulated in the solution, their reaction with metallic copper becomes possible [32]:

$$
\mathrm{Cu}^{2+}+\mathrm{Cu}=2 \mathrm{Cu}^{+} \text {. }
$$

In turn, the $\mathrm{Cu}(\mathrm{I})$ cations formed in the solution will be oxidized again by oxygen to $\mathrm{Cu}(\mathrm{II})$. Altogether, this effect must lead in time to acceleration of copper corrosion. It is known that in the case of acid solutions containing additional oxidants (oxygen, metal cations), participation of the latter in metal corrosion causes acceleration of the cathodic process. Besides, reduction of additional oxidants occurs under diffusion control [33]. As oxygen and $\mathrm{Cu}$ (II) cations are the oxidants in the system under consideration, one might make the assumption that the corrosion process on the whole is controlled by diffusion and its rate must considerably depend on the hydrodynamic parameters of the corrosive medium.

In view of this, it appears expedient to study the regularities of copper corrosion in $\mathrm{C}_{6} \mathrm{H}_{8} \mathrm{O}_{7}$ solutions and also to consider the possibility of its protection by inhibitors. The corrosion inhibitor studied is IFKhAN-92, while the compound used as a reference is the commercial cationic surfactant, Catamine $\mathrm{AB}$ (alkylbenzyldimethylammonium chloride $\left[\mathrm{C}_{n} \mathrm{H}_{2 n+1} \mathrm{~N}^{+}\left(\mathrm{CH}_{3}\right)_{2} \mathrm{CH}_{2} \mathrm{C}_{6} \mathrm{H}_{5}\right] \mathrm{Cl}^{-}$, where $\left.n=10-18\right)$. The factors to be assessed include the duration of corrosion tests, $\mathrm{C}_{6} \mathrm{H}_{8} \mathrm{O}_{7}$ concentration, the presence of the corrosion product $\mathrm{Cu}$ (II) cations, the presence of corrosion inhibitors, and convection that may affect copper corrosion in the medium in question.

\section{Experimental}

The corrosion rate of $\mathrm{M} 1$ copper (up to $0.005 \mathrm{Fe}$; up to $0.002 \mathrm{Ni}$; up to $0.004 \mathrm{~S}$; up to $0.002 \mathrm{As}$; up to $0.005 \mathrm{~Pb}$; up to $0.004 \mathrm{Zn}$; up to $0.05 \mathrm{O}$; up to $0.002 \mathrm{Sb}$; up to $0.001 \mathrm{Bi}$; up to $0.002 \mathrm{Sn} ; \mathrm{Cu}(99.90)$ ) in $\mathrm{C}_{6} \mathrm{H}_{8} \mathrm{O}_{7}$ solutions was determined from the sample mass loss (at least three samples per point) using the sample size of $50.0 \times 30.0 \times 1.0 \mathrm{~mm}$ per $165 \mathrm{ml}$ of the acid solution at a temperature of $t=20 \pm 2^{\circ} \mathrm{C}$. Prior to an experiment, the samples were 
cleaned on P 600 sandpaper and degreased with acetone. The experiment duration was 1-20 days.

The effect of convection on the copper corrosion rate was studied in $\mathrm{C}_{6} \mathrm{H}_{8} \mathrm{O}_{7}$ solutions stirred with a magnetic stirrer at rotation rates of $n=0,250,420$ and $750 \mathrm{rpm}$.

The efficiency of inhibitors was estimated by protection degrees:

$$
Z=\frac{k_{0}-k_{\text {in }}}{k_{0}} \cdot 100 \%,
$$

where $k_{0}$ and $k_{\text {in }}$ are the corrosion rates in the background solution and in a solution with an additive being studied.

$\mathrm{C}_{6} \mathrm{H}_{8} \mathrm{O}_{7} \cdot \mathrm{H}_{2} \mathrm{O}$ (GOST 908-2004) and distilled water were used for solution preparation. The basic concentration of IFKhAN-92 and Catamine $\mathrm{AB}$ was $C_{\mathrm{in}}=0.5 \mathrm{mM}$. As the solubility of IFKhAN-92 in $\mathrm{C}_{6} \mathrm{H}_{8} \mathrm{O}_{7}$ solutions is low, it was added as a solution in ethanol.

Copper(II) citrate solutions were obtained by the reaction of basic copper(II) carbonate with $\mathrm{C}_{6} \mathrm{H}_{8} \mathrm{O}_{7}$. Basic copper(II) carbonate was obtained by precipitation with sodium hydrocarbonate ("chemically pure" grade) from copper(II) sulfate ("pure" grade) solution followed by long-term rinsing of the precipitate with distilled water.

\section{Results and Discussion}

Copper corrosion in $0.5 \mathrm{M} \mathrm{C}_{6} \mathrm{H}_{8} \mathrm{O}_{7}$ occurs relatively slowly (Table 1). Note that the sample mass loss $(\Delta m)$ in the course of long-term corrosion tests (20 days) reaches a significant value of $30 \mathrm{~g} / \mathrm{m}^{2}$. The mean copper corrosion rate $k$ weakly depends on the duration of exposure of metallic samples to the corrosive medium. The maximum $k$ value was obtained after 2 and 13 days of tests: $0.071 \mathrm{~g} /\left(\mathrm{m}^{2} \cdot \mathrm{h}\right)$. The content of $\mathrm{C}_{6} \mathrm{H}_{8} \mathrm{O}_{7}$ in a solution weakly affects the $k$ value of copper (Table 2). The result obtained is in good agreement with the fact that copper is oxidized by the air oxygen dissolved in a corrosive medium studied whose content is similar in these solutions, rather than by citric acid. Accumulation of $\mathrm{Cu}$ (II) cations in the corrosive medium reduces its corrosivity somewhat (Table 3). In fact, the $k$ value of copper decrease 1.2-fold in the presence of $0.05 \mathrm{M} \mathrm{Cu}$ (II).

These results on the copper corrosion in $\mathrm{C}_{6} \mathrm{H}_{8} \mathrm{O}_{7}$ solutions correspond to static conditions that are rarely encountered under industrial conditions. More often, metals contact a stream of a corrosive medium. In ceases where the corrosion process is controlled by diffusion limitations, this may result in a considerable acceleration of metal degradation.

In naturally aerated $2 \mathrm{M} \mathrm{C}_{6} \mathrm{H}_{8} \mathrm{O}_{7}$, the effect of forced convection $(n=750 \mathrm{rpm})$ on corrosion is significant. The corrosion loss gain is $213 \%$ (Table 4 ). The effect of forced convection on $k$ of copper in naturally aerated $2 \mathrm{M} \mathrm{C}_{6} \mathrm{H}_{8} \mathrm{O}_{7}+0.05 \mathrm{M} \mathrm{Cu}(\mathrm{II})$ is also significant. The $k$ values of copper in a static and dynamic $(n=750 \mathrm{rpm})$ medium differ by a factor of 3.2. In freely aerated $2 \mathrm{M} \mathrm{C}_{6} \mathrm{H}_{8} \mathrm{O}_{7}+0.05 \mathrm{M} \mathrm{Cu}(\mathrm{II})$, copper corrosion occurs due to the presence of two oxidants in the corrosive medium: molecular oxygen and $\mathrm{Cu}$ (II) cations. It seems of interest to establish the effective copper corrosion rates in this medium related solely to the presence of $\mathrm{Cu}$ (II) cations by calculating them as a difference in the $k$ of copper in aerated acid 
solutions in the presence and in the absence of $0.05 \mathrm{M} \mathrm{Cu}$ (II). This approach is correct on the assumption of independent corrosion processes on copper caused by the presence of molecular oxygen and $\mathrm{Cu}$ (II) in an $\mathrm{C}_{6} \mathrm{H}_{8} \mathrm{O}_{7}$ solution. The effective $k$ of copper due only to the presence of $\mathrm{Cu}$ (II) cations is sensitive to convective effects. The effective $k$ values of copper in static and dynamic $(n=750 \mathrm{rpm})$ media differ 3.4-fold.

Table 1. Effect of the duration of exposure of copper samples in $2 \mathrm{M} \mathrm{C}_{6} \mathrm{H}_{8} \mathrm{O}_{7}\left(20 \pm 2^{\circ} \mathrm{C}\right)$ on the mass loss $(\Delta m)$, corrosion rate $(k)$, and degree of metal protection by the inhibitor $(Z)$.

\begin{tabular}{|c|c|c|c|c|c|c|}
\hline \multirow{2}{*}{$\begin{array}{c}\text { Corrosion process } \\
\text { parameter }\end{array}$} & \multicolumn{6}{|c|}{ Exposure time, days } \\
\hline & 1 & 2 & 4 & 8 & 13 & 20 \\
\hline \multicolumn{7}{|c|}{ Without an inhibitor } \\
\hline$\Delta m, \mathrm{~g} / \mathrm{m}^{2}$ & 1.7 & 3.4 & 5.9 & 13 & 22 & 30 \\
\hline$k, \mathrm{~g} /\left(\mathrm{m}^{2} \cdot \mathrm{h}\right)$ & 0.071 & 0.071 & 0.061 & 0.068 & 0.071 & 0.063 \\
\hline \multicolumn{7}{|c|}{$0.5 \mathrm{mM}$ Catamine $\mathrm{AB}$} \\
\hline$\Delta m, \mathrm{~g} / \mathrm{m}^{2}$ & 0.89 & 1.0 & 1.6 & 2.2 & 4.3 & 5.7 \\
\hline$k, \mathrm{~g} /\left(\mathrm{m}^{2} \cdot \mathrm{h}\right)$ & 0.037 & 0.021 & 0.017 & 0.011 & 0.014 & 0.012 \\
\hline$Z, \%$ & 47.6 & 70.6 & 72.9 & 83.1 & 80.5 & 81.0 \\
\hline \multicolumn{7}{|c|}{0.5 mM IFKhAN-92 } \\
\hline$\Delta m, \mathrm{~g} / \mathrm{m}^{2}$ & 0.33 & 0.56 & 0.93 & 1.6 & 3.2 & 4.5 \\
\hline$k, \mathrm{~g} /\left(\mathrm{m}^{2} \cdot \mathrm{h}\right)$ & 0.014 & 0.012 & 0.010 & 0.008 & 0.010 & 0.009 \\
\hline$Z, \%$ & 80.6 & 83.5 & 84.2 & 87.7 & 85.5 & 85.0 \\
\hline \multicolumn{7}{|c|}{$1 \mathrm{mM}$ IFKhAN-92 } \\
\hline$\Delta m, \mathrm{~g} / \mathrm{m}^{2}$ & - & - & - & 1.2 & - & 3.3 \\
\hline$k, \mathrm{~g} /\left(\mathrm{m}^{2} \cdot \mathrm{h}\right)$ & - & - & - & 0.006 & - & 0.007 \\
\hline$Z, \%$ & - & - & - & 91.2 & - & 88.8 \\
\hline \multicolumn{7}{|c|}{5 mM IFKhAN-92 } \\
\hline$\Delta m, \mathrm{~g} / \mathrm{m}^{2}$ & - & - & - & 1.2 & - & 2.4 \\
\hline$k, \mathrm{~g} /\left(\mathrm{m}^{2} \cdot \mathrm{h}\right)$ & - & - & - & 0.006 & - & 0.005 \\
\hline$Z, \%$ & - & - & - & 91.2 & - & 92.1 \\
\hline
\end{tabular}


Table 2. Effect of the concentration of $\mathrm{C}_{6} \mathrm{H}_{8} \mathrm{O}_{7}\left(20 \pm 2^{\circ} \mathrm{C}\right)$ on the rate of copper corrosion $(k)$ and degree of metal protection by the inhibitor $(Z)$ based on the data of 8 -day tests.

\begin{tabular}{|c|c|c|c|c|c|c|c|c|}
\hline \multirow{2}{*}{ Corrosion process parameter } & \multicolumn{8}{|c|}{$C\left(\mathrm{C}_{6} \mathrm{H}_{8} \mathrm{O}_{7}\right), \mathbf{M}$} \\
\hline & 0.001 & 0.005 & 0.01 & 0.05 & 0.1 & 0.5 & 1 & 2 \\
\hline \multicolumn{9}{|c|}{ Without an inhibitor } \\
\hline$k, \mathrm{~g} /\left(\mathrm{m}^{2} \cdot \mathrm{h}\right)$ & 0.041 & 0.047 & 0.050 & 0.052 & 0.057 & 0.068 & 0.052 & 0.045 \\
\hline \multicolumn{9}{|c|}{$0.5 \mathrm{mM}$ Catamine $\mathrm{AB}$} \\
\hline$k, \mathrm{~g} /\left(\mathrm{m}^{2} \cdot \mathrm{h}\right)$ & 0.010 & 0.011 & 0.011 & 0.011 & 0.012 & 0.011 & 0.011 & 0.010 \\
\hline$Z, \%$ & 73.2 & 76.6 & 78.0 & 78.8 & 78.9 & 83.1 & 78.8 & 77.8 \\
\hline \multicolumn{9}{|c|}{$0.5 \mathrm{mM}$ IFKhAN-92 } \\
\hline$k, \mathrm{~g} /\left(\mathrm{m}^{2} \cdot \mathrm{h}\right)$ & 0.008 & 0.009 & 0.010 & 0.009 & 0.009 & 0.008 & 0.008 & 0.005 \\
\hline$Z, \%$ & 80.5 & 80.9 & 80.0 & 82.7 & 84.2 & 87.7 & 84.6 & 88.9 \\
\hline
\end{tabular}

Table 3. Effect of the concentration of copper(II) cations on the rate of copper corrosion in $2 \mathrm{M} \mathrm{C}_{6} \mathrm{H}_{8} \mathrm{O}_{7}$ $\left(20 \pm 2^{\circ} \mathrm{C}\right)$ based on the data of 4-day tests.

\section{Corrosion process parameter}

$$
C_{\mathrm{Cu}(\mathrm{II})}, \mathrm{M}
$$

\begin{tabular}{lll}
\hline 0 & 0.025 & 0.050
\end{tabular}

Without an inhibitor

$\begin{array}{crcc}k, \mathrm{~g} /\left(\mathrm{m}^{2} \cdot \mathrm{h}\right) & 0.049 & 0.045 & 0.042 \\ & 0.5 \mathrm{mM} \text { Catamine AB } & \\ k, \mathrm{~g} /\left(\mathrm{m}^{2} \cdot \mathrm{h}\right) & 0.013 & 0.027 & 0.027 \\ Z, \% & 73.5 & 40.0 & 35.7 \\ k, \mathrm{~g} /\left(\mathrm{m}^{2} \cdot \mathrm{h}\right) & 0.010 & 0.009 & 0.012 \\ Z, \% & 79.6 & 80.0 & 71.4\end{array}$


Table 4. Effect of the convective factor on the copper corrosion in $2 \mathrm{M} \mathrm{C}_{6} \mathrm{H}_{8} \mathrm{O}_{7}\left(20 \pm 2^{\circ} \mathrm{C}\right)$ based on oneday tests.

\section{Without an inhibitor $\quad 0.5 \mathrm{mM}$ Catamine AB $\quad 0.5 \mathrm{mM}$ IFKhAN-92}

Corrosion process parameter

\section{Rotation rate of the magnetic stirrer, rpm}

\begin{tabular}{ccccccc} 
& $\mathbf{0}$ & $\mathbf{7 5 0}$ & $\mathbf{0}$ & $\mathbf{7 5 0}$ & $\mathbf{0}$ & $\mathbf{7 5 0}$ \\
\hline $\mathrm{n}, \mathrm{g} /\left(\mathrm{m}^{2} \cdot \mathrm{h}\right)$ & $2 \mathrm{M} \mathrm{C}_{6} \mathrm{H}_{8} \mathrm{O}_{7}$ (free aeration) \\
$Z, \%$ & 0.040 & 0.125 & 0.014 & 0.025 & 0.009 & 0.014 \\
\hline
\end{tabular}

$2 \mathrm{M} \mathrm{C}_{6} \mathrm{H}_{8} \mathrm{O}_{7}+0.05 \mathrm{M} \mathrm{Cu}(\mathrm{II})$ (free aeration)

$\begin{array}{ccccccc}k, \mathrm{~g} /\left(\mathrm{m}^{2} \cdot \mathrm{h}\right) & 0.049 & 0.156 & 0.023 & 0.036 & 0.018 & 0.024 \\ Z, \% & - & - & 53.1 & 76.9 & 63.3 & 84.6\end{array}$

$2 \mathrm{M} \mathrm{C}_{6} \mathrm{H}_{8} \mathrm{O}_{7}+0.05 \mathrm{M} \mathrm{Cu}(\mathrm{II})^{*}$

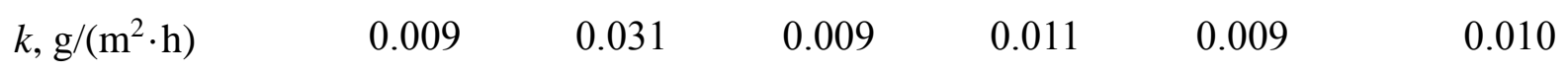
$Z, \%$
$\begin{array}{lllll}- & - & -\end{array}$
64.5
67.7

Analysis of the dependences of the copper corrosion rate on the magnetic stirrer rotation frequency in freely aerated $2 \mathrm{M} \mathrm{C}_{6} \mathrm{H}_{8} \mathrm{O}_{7}$ and $2 \mathrm{M} \mathrm{C}_{6} \mathrm{H}_{8} \mathrm{O}_{7}+0.05 \mathrm{M} \mathrm{Cu}$ (II) (Table 5, Figure 1) showed that, formally, it is fairly described by the equation: $k=a+b \cdot n^{1 / 2}$. The form of this equation is typical of concurrent processes under kinetic and diffusion control [34]. Parameter $a$ characterizes the kinetic component, while $b$ corresponds to diffusion. In our system, however, it is more correct to relate parameter $a$ to metal corrosion due to natural convection of the corrosive medium in long-term static tests.

Table 5. Parameters $a$ and $b$ of the kinetic equation $k=a+b \cdot n^{1 / 2}$ for copper corrosion in $2 \mathrm{M} \mathrm{C}_{6} \mathrm{H}_{8} \mathrm{O}_{7}$ $\left(20 \pm 2^{\circ} \mathrm{C}\right)$ based on 1-day tests.

\begin{tabular}{ccc}
\hline Inhibitor & $\boldsymbol{a , ~} /\left(\mathbf{m}^{\mathbf{2}} \cdot \mathbf{h}\right)$ & $\boldsymbol{b}, \mathbf{g} /\left(\mathbf{m}^{\mathbf{2}} \cdot \mathbf{h} \cdot \mathbf{r p m} \mathbf{m}^{\mathbf{1} \mathbf{2}}\right)$ \\
\hline & $2 \mathrm{M} \mathrm{C}_{6} \mathrm{H}_{8} \mathrm{O}_{7}$ & \\
\hline Without an inhibitor & 0.040 & 0.0031 \\
$0.5 \mathrm{mM}$ Catamine $\mathrm{AB}$ & 0.014 & 0.0004 \\
$0.5 \mathrm{mM}$ IFKhAN-92 & 0.009 & 0.0002 \\
\hline
\end{tabular}




\begin{tabular}{|c|c|c|}
\hline Inhibitor & $a, \mathbf{g} /\left(\mathbf{m}^{2} \cdot \mathbf{h}\right)$ & $b, \mathbf{g} /\left(\mathbf{m}^{2} \cdot \mathbf{h} \cdot \mathbf{r p m} \mathbf{m}^{1 / 2}\right)$ \\
\hline \multicolumn{3}{|c|}{$2 \mathrm{M} \mathrm{C}_{6} \mathrm{H}_{8} \mathrm{O}_{7}+0.05 \mathrm{M} \mathrm{Cu}(\mathrm{II})$} \\
\hline Without an inhibitor & 0.049 & 0.0039 \\
\hline $0.5 \mathrm{mM}$ Catamine $\mathrm{AB}$ & 0.023 & 0.0005 \\
\hline 0.5 mM IFKhAN-92 & 0.018 & 0.0002 \\
\hline
\end{tabular}

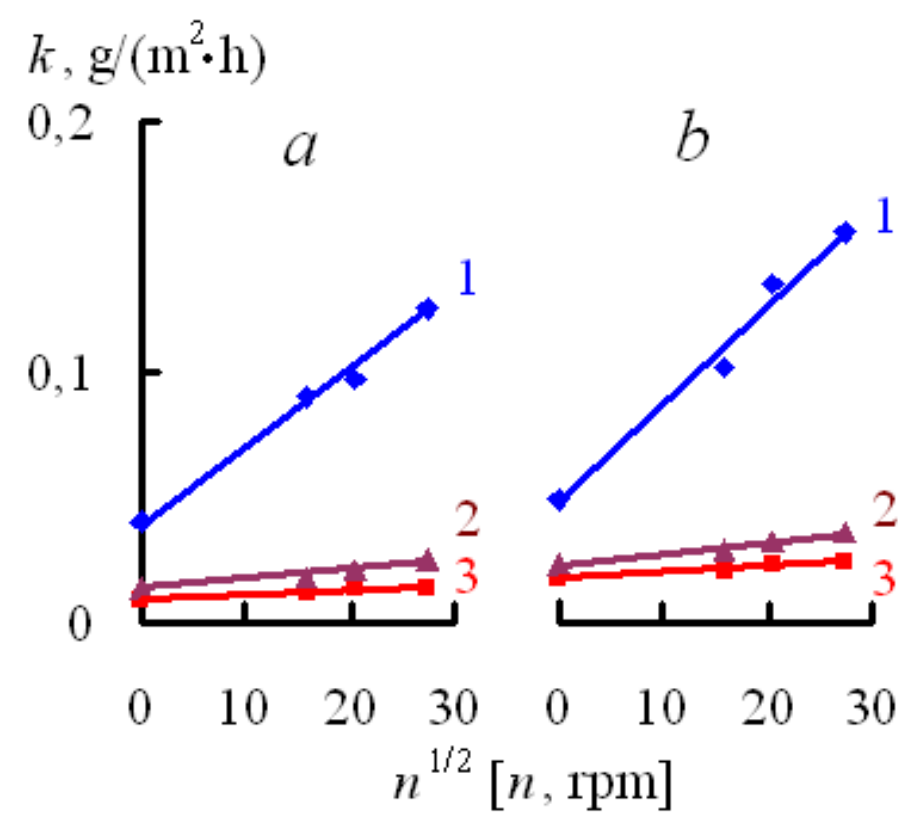

Figure 1. Plots of the copper corrosion rate in $2 \mathrm{M} \mathrm{C}_{6} \mathrm{H}_{8} \mathrm{O}_{7}(a)$ and $2 \mathrm{M} \mathrm{C}_{6} \mathrm{H}_{8} \mathrm{O}_{7}+0.05 \mathrm{M}$ $\mathrm{Cu}$ (II) $(b)\left(20 \pm 2^{\circ} \mathrm{C}\right)$ based on the data of 1-day tests versus the frequency of solution stirring by a magnetic stirrer. 1 - without an inhibitor, $2-0.5 \mathrm{mM}$ Catamine $\mathrm{AB}, 3-0.5 \mathrm{mM}$ IFKhAN-92.

Thus, $\mathrm{C}_{6} \mathrm{H}_{8} \mathrm{O}_{7}$ solutions, especially in the absence of prolonged contact with copper, are relatively weakly corrosive to the latter. This is typical of both static and dynamic corrosion conditions. Under static conditions, accumulation of the corrosion product, $\mathrm{Cu}$ (II) cations, in the acid also fails to affect copper corrosion. Meanwhile, accumulation of $\mathrm{Cu}$ (II) cations in citric solutions together with dynamic corrosion conditions is capable of considerably enhancing the solution corrosivity, which is extremely undesirable.

According to the data of 8-day tests, the Catamine AB additive $\left(C_{\mathrm{in}}=0.05-5 \mathrm{mM}\right)$ in $0.5 \mathrm{M} \mathrm{C}_{6} \mathrm{H}_{8} \mathrm{O}_{7}$ inhibits copper corrosion 3.1-6.2 fold (Table 6). At $C_{\text {in }} \geq 0.05 \mathrm{mM}, Z>80 \%$, while at $C_{\text {in }} \geq 0.5 \mathrm{mM}, Z$ is independent of the inhibitor content. A similar amount of IFKhAN-92 lowers the $k$ of copper 3.8-11 fold. In the $C_{\text {in }}$ range studied, $Z>73.5 \%$, while at $C_{\text {in }} \geq 1 \mathrm{mM}, Z$ is independent of the content of IFKhAN-92. 
Table 6. ${ }^{*}$ Effect of the inhibitor concentration on the copper corrosion rate in $2 \mathrm{M} \mathrm{C}_{6} \mathrm{H}_{8} \mathrm{O}_{7}\left(20 \pm 2{ }^{\circ} \mathrm{C}\right)$ based on 8-day tests.

\begin{tabular}{cccccc}
\hline & \multicolumn{7}{c}{$\boldsymbol{C}_{\text {in, }} \mathbf{m M}$} \\
\cline { 2 - 6 } Corrosion process parameter & $\mathbf{0 . 0 5}$ & $\mathbf{0 . 1}$ & $\mathbf{0 . 5}$ & $\mathbf{1}$ & $\mathbf{5}$ \\
\cline { 2 - 6 } & \multicolumn{7}{c}{ Catamine AB } \\
\hline$k, \mathrm{~g} /\left(\mathrm{m}^{2} \cdot \mathrm{h}\right)$ & 0.022 & 0.012 & 0.011 & 0.011 & 0.011 \\
$Z, \%$ & 67.6 & 82.4 & 83.1 & 83.1 & 83.1 \\
\hline & \multicolumn{7}{c}{ IFKhAN-92 } \\
\hline$k, \mathrm{~g} /\left(\mathrm{m}^{2} \cdot \mathrm{h}\right)$ & 0.018 & 0.010 & 0.008 & 0.006 & 0.006 \\
$Z, \%$ & 73.5 & 85.3 & 87.7 & 91.2 & 91.2 \\
\hline
\end{tabular}

*The copper corrosion rate in $2 \mathrm{M} \mathrm{C}_{6} \mathrm{H}_{8} \mathrm{O}_{7}\left(20 \pm 2^{\circ} \mathrm{C}\right)$ is $0.068 \mathrm{~g} /\left(\mathrm{m}^{2} \cdot \mathrm{h}\right)$.

Both studied inhibitors retain their protective effect in $0.5 \mathrm{M} \mathrm{C}_{6} \mathrm{H}_{8} \mathrm{O}_{7}$ for at least 20 days (Table 1). The addition of $0.5 \mathrm{mM}$ Catamine $\mathrm{AB}$ slows down copper corrosion by a factor of 1.9-5.9, while IFKhAN-92 inhibits it by a factor of 5.2-8.1, i.e., more strongly. It is possible to reduce the $k$ of copper by a factor of 12.6 with a sample exposure time of 20 days,

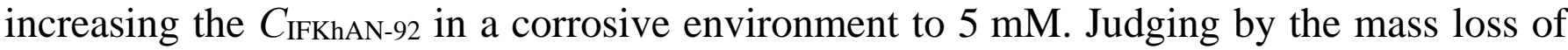
sample over time, in the presence of both inhibitors, copper corrosion is the fastest in the first day, after which the process slows down. Both organic compounds studied inhibit copper corrosion in a wide range of $C\left(\mathrm{C}_{6} \mathrm{H}_{8} \mathrm{O}_{7}\right)=0.001-2 \mathrm{M}$ (Table 2). The protective effect of IFKhAN-92 is better than that of Catamine AB.

In a static corrosive medium, the presence of $\mathrm{Cu}$ (II) has an adverse effect on the copper protection by Catamine $\mathrm{AB}$ (Table 3). The presence of $0.1 \mathrm{M} \mathrm{Cu}$ (II) enhances the $k$ of copper by a factor of 2.1 compared to the medium free of $\mathrm{Cu}(\mathrm{II})$. In contrast, IFKhAN-92 accelerates corrosion only 1.2-fold under similar conditions. This is rather an interesting result, as it is known that the presence of metal cations with oxidizing properties in a corrosive medium causes a significant weakening of the protective effect of acid corrosion inhibitors [35]. This regularity is clearly demonstrated by Catamine $\mathrm{AB}$ in the medium we were studying. On the contrary, IFKhAN-92 is quite resistant to the presence of $\mathrm{Cu}$ (II) cations in the corrosive medium. Earlier [36], the unique ability of IFKhAN-based composite inhibitors to preserve their protective effect was shown in the case of mild steel corrosion in acid media containing $\mathrm{Fe}(\mathrm{III})$ salts. A similar effect is characteristic of copper corrosion in acetic acid in the presence of $\mathrm{Cu}\left(\mathrm{H}_{3} \mathrm{CCOO}\right)_{2}$ [31].

It is important to understand whether efficient copper corrosion inhibition is maintained in $\mathrm{C}_{6} \mathrm{H}_{8} \mathrm{O}_{7}$ solutions on transition from static corrosion to corrosion under dynamic conditions. Indeed, the $k$ values of copper in freely aerated $2 \mathrm{M} \mathrm{C}_{6} \mathrm{H}_{8} \mathrm{O}_{7}$ in the presence of 
$0.5 \mathrm{mM}$ Catamine $\mathrm{AB}$ under static conditions and under dynamic $(n=750 \mathrm{rpm})$ conditions differ 1.8-fold (Table 4). In this case, the protective effect of the inhibitor decreases to $80 \%$. In the case of $0.5 \mathrm{mM}$ IFKhAN-92, corrosion is also accelerated 1.6-fold, but the $Z$ value remains much higher $(88.8 \%)$, since the $k$ of copper is considerably lower in the presence of this compound.

The addition of Catamine $\mathrm{AB}$ demonstrates a poorer result than that of IFKhAN-92 in freely aerated $2 \mathrm{M} \mathrm{C}_{6} \mathrm{H}_{8} \mathrm{O}_{7}+0.05 \mathrm{M} \mathrm{Cu}(\mathrm{II})$. Interestingly, corrosion is accelerated in the presence of both inhibitors under dynamic conditions $(n=750 \mathrm{rpm})$ in comparison with the data of static tests. Nevertheless, on the whole, the protective effect is better under dynamic conditions. This effect is due to a significant acceleration of copper corrosion in the background medium in a stirred solution. Similar regularities are also typical of the effective contribution of $\mathrm{Cu}$ (II) cations to the corrosion process.

In inhibited media, the dependences of the copper corrosion rate on the magnetic stirrer rotation rate in freely aerated $2 \mathrm{M} \mathrm{C}_{6} \mathrm{H}_{8} \mathrm{O}_{7}$ and $2 \mathrm{M} \mathrm{C}_{6} \mathrm{H}_{8} \mathrm{O}_{7}+0.05 \mathrm{M} \mathrm{Cu}$ (II), like in the background medium, are satisfactorily described by the equation: $k=a+b \cdot n^{1 / 2}$ (Table 5 , Figure 1). In the presence of inhibitors, parameters $a$ and $b$ are reduced in comparison with the background solution. This effect is most pronounced in the presence of IFKhAN-92.

Thus, the IFKhAN-92 inhibitor efficiently slows down copper corrosion in $\mathrm{C}_{6} \mathrm{H}_{8} \mathrm{O}_{7}$ solutions. It retains its protective effect if the corrosion product, $\mathrm{Cu}$ (II) cations, is accumulated in $\mathrm{C}_{6} \mathrm{H}_{8} \mathrm{O}_{7}$ solutions. It is important to note that IFKhAN-92 protects copper both in static and dynamic corrosive media. Under all experimental conditions, the IFKhAN-92 inhibitor provides $Z>63.6 \%$, while the largest $k$ of copper observed under severe corrosion conditions $(0.05 \mathrm{M} \mathrm{Cu}(\mathrm{II}), n=750 \mathrm{rpm})$ is as small as $0.024 \mathrm{~g} /\left(\mathrm{m}^{2} \cdot \mathrm{h}\right)$. Under similar conditions, Catamine AB is inferior to IFKhAN-92 as regards the inhibition of copper corrosion.

The results obtained are important from the practical point of view, since they open new prospects for using $\mathrm{C}_{6} \mathrm{H}_{8} \mathrm{O}_{7}$ solutions where they potentially can come into contact with metallic copper. The corrosion rate in $\mathrm{C}_{6} \mathrm{H}_{8} \mathrm{O}_{7}$ solutions is rather low, $k=0.041-0.071 \mathrm{~g} /\left(\mathrm{m}^{2} \cdot \mathrm{h}\right)$, but accumulation of the corrosion product, $\mathrm{Cu}$ (II) cations, combined with forced convection of the medium may cause its increase to $0.156 \mathrm{~g} /\left(\mathrm{m}^{2} \cdot \mathrm{h}\right)$. If $0.5 \mathrm{mM}$ IFKhAN-92 is used for copper protection, then, irrespective of the hydrodynamic mode in an $\mathrm{C}_{6} \mathrm{H}_{8} \mathrm{O}_{7}$ solution and the presence of $\mathrm{Cu}$ (II) cations, the $k$ value for copper is $0.005-0.024 \mathrm{~g} /\left(\mathrm{m}^{2} \cdot \mathrm{h}\right)$, which is a good result.

It is important to understand the origin of the higher inhibitor effect of the IFKhAN-92 triazole derivative in comparison with Catamine $\mathrm{AB}$. They largely due to the unique regularities of the mechanism of the protective action of triazoles [37]. These compounds can be chemosorbed on the surface of a metal being protected followed by the formation of polymolecular protective surface layers that are extremely efficient in corrosion inhibition.

The results presented in this paper deal with the specifics of the corrosion behavior of copper in citric acid media and the effect of corrosion inhibitors on this process. The discussion of the reasons for the observed regularities of the corrosion behavior of copper is 
tentative and requires additional studies involving electrochemical and physicochemical methods. Their results will be presented in our further papers on this subject.

\section{Conclusions}

1. The copper corrosion rate in freely aerated acetic acid solutions weakly depends on the duration of contact between copper and the corrosive medium and on the concentration of $\mathrm{C}_{6} \mathrm{H}_{8} \mathrm{O}_{7}$. The corrosivity of these solutions toward copper increases significantly in case of transition from static to dynamic conditions.

2. The corrosivity of $\mathrm{C}_{6} \mathrm{H}_{8} \mathrm{O}_{7}$ solutions toward copper is enhanced in the presence of $\mathrm{Cu}$ (II) cations. This effect is most noticeable when copper comes into contact with a moving corrosive medium.

3. The IFKhAN-92 inhibitor can be used for copper protection in freely aerated $\mathrm{C}_{6} \mathrm{H}_{8} \mathrm{O}_{7}$ solutions. The efficiency of this compound does not depend considerably on the duration of contact between the metal and the corrosive medium, the $\mathrm{C}_{6} \mathrm{H}_{8} \mathrm{O}_{7}$ content, and the hydrodynamic parameters. An important feature of the IFKhAN-92 inhibitor is that it maintains protection of copper even where $\mathrm{Cu}$ (II) cations is accumulated in the corrosive medium. This effect is observed not only in static but also in dynamic media.

4. The protective effect of IFKhAN-92 toward copper in $\mathrm{C}_{6} \mathrm{H}_{8} \mathrm{O}_{7}$ solutions is much stronger than that of Catamine $\mathrm{AB}$, a well-known inhibitor of acid metal corrosion.

5. The dependence of the copper corrosion rate on the convective factor in freely aerated $2 \mathrm{M} \mathrm{C}_{6} \mathrm{H}_{8} \mathrm{O}_{7}$ and $2 \mathrm{M} \mathrm{C}_{6} \mathrm{H}_{8} \mathrm{O}_{7}+0.05 \mathrm{M} \mathrm{Cu}$ (II), both in the absence and in the presence of corrosion inhibitors, is formally described by the equation: $k=a+b \cdot n^{1 / 2}$, where $n$ is the rotation frequency of the magnetic stirrer. The addition of the inhibitors studied, especially IFKhAN-92, decrease the parameters $a$ and $b$ in this equation.

\section{Acknowledgements}

The study was carried out under the Fundamental Scientific Research Program of the State Academies of Sciences for 2013-2020: "Development of the fundamental scientific foundations of the protective effect of metal corrosion inhibitors in gas and condensed media, nanocomposites, paints and conversion coatings" (State registration number AAAA-A18118121090043-0).

\section{References}

1. C. Verma, M.A. Quraishi and E.E. Ebenso, Corrosive electrolytes, Int. J. Corros. Scale Inhib., 2020, 9, no. 4, 1261-1276. doi: 10.17675/2305-6894-2020-9-4-5

2. Ya.G. Avdeev and Yu.I. Kuznetsov, Inhibitory protection of steels from hightemperature corrosion in acid solutions. A review. Part 1, Int. J. Corros. Scale Inhib., 2020, 9, no. 2, 394-426. doi: 10.17675/2305-6894-2020-9-2-2 
3. D.K. Verma, E.E. Ebenso, M.A. Quraishi and C. Verma, Gravimetric, electrochemical surface and density functional theory study of acetohydroxamic and benzohydroxamic acids as corrosion inhibitors for copper in $1 \mathrm{M} \mathrm{HCl}$, Results Phys., 2019, 13, 102194. doi: 10.1016/j.rinp.2019.102194

4. K.El Mouaden, D.S. Chauhan, M.A. Quraishi, L. Bazzi and M. Hilali, Cinnamaldehydemodified chitosan as a bio-derived corrosion inhibitor for acid pickling of copper: Microwave synthesis, experimental and computational study, Int. J. Biol. Macromol., 2020, 164, 3709-3717. doi: 10.1016/j.ijbiomac.2020.08.137

5. R.K. Ahmed and S. Zhang, Bee pollen extract as an eco-friendly corrosion inhibitor for pure copper in hydrochloric acid, J. Mol. Liq., 2020, 316, 113849. doi: 10.1016/j.molliq.2020.113849

6. M. Behpour, S.M. Ghoreishi, M. Salavati-Niasari and B. Ebrahimi, Evaluating two new synthesized S-N Schiff bases on the corrosion of copper in $15 \%$ hydrochloric acid, Mater. Chem. Phys., 2008, 107, no. 1, 153-157. doi: 10.1016/j.matchemphys.2007.06.068

7. M.N. El-Haddad, Chitosan as a green inhibitor for copper corrosion in acidic medium, Int. J. Biol. Macromol., 2013, 55, 142-149. doi: 10.1016/j.ijbiomac.2012.12.044

8. L. Larabi, O. Benali, S.M. Mekelleche and Y. Harek, 2-Mercapto-1-methylimidazole as corrosion inhibitor for copper in hydrochloric acid, Appl. Surf. Sci., 2006, 253, no. 3, 1371-1378. doi: 10.1016/j.apsusc.2006.02.013

9. El-Sayed M. Sherif, R.M. Erasmus and J.D. Comins, Inhibition of copper corrosion in acidic chloride pickling solutions by 5-(3-aminophenyl)-tetrazole as a corrosion inhibitor, Corros. Sci., 2008, 50, no. 12, 3439-3445. doi: 10.1016/j.corsci.2008.10.002

10. D.Q. Zhang, Q.R. Cai, L.X. Gao and K.Y. Lee, Effect of serine, threonine and glutamic acid on the corrosion of copper in aerated hydrochloric acid solution, Corros. Sci., 2008, 50, no. 12, 3615-3621. doi: 10.1016/j.corsci.2008.09.007

11. D.Q. Zhang, H. Wu and L.X. Gao, Synergistic inhibition effect of 1-phenylalanine and rare earth $\mathrm{Ce}(\mathrm{IV})$ ion on the corrosion of copper in hydrochloric acid solution, Mater. Chem. Phys., 2012, no. 2-3, 133, 981-986. doi: 10.1016/j.matchemphys.2012.02.001

12. L. Zhou, S. Zhang, B. Tan, L. Feng, B. Xiang, F. Chen, W. Li, B. Xiong and T. Song, Phenothiazine drugs as novel and eco-friendly corrosion inhibitors for copper in sulfuric acid solution, J. Taiwan Inst. Chem. Eng., 2020, 113, 253-263. doi: 10.1016/j.jtice.2020.08.018

13. I. Cakmakc1, B. Duran and G. Bereket, Influence of electrochemically prepared poly(pyrrole-co-N-methylpyrrole) and poly(pyrrole)/poly(N-methylpyrrole) composites on corrosion behavior of copper in acidic medium, Prog. Org. Coat., 2013, 76, no. 1, 70-77. doi: $10.1016 /$ j.porgcoat.2012.08.015

14. L. Guo, B. Tan, X.Zuo, W. Li, S. Leng and X. Zheng, Eco-friendly food spice 2Furfurylthio-3-methylpyrazine as an excellent inhibitor for copper corrosion in sulfuric acid medium, J. Mol. Liq., 2020, 317, 113915. doi: 10.1016/j.molliq.2020.113915 
15. G. Trabanelli, A. Frignani, C. Monticelli and F. Zucchi, Alkyl-benzotriazole derivatives as inhibitors of iron and copper corrosion, Int. J. Corros. Scale Inhib., 2015, 4, no. 1, 96-107. doi: 10.17675/2305-6894-2015-4-1-096-107

16. D. Shevtsov, O. Kozaderov, Kh. Shikhaliev, E. Komarova, Al. Kruzhilin, A. Potapov, C. Prabhakar and I. Zartsyn, 3-Sulphinyl-5-Amino-1H-1,2,4-Triazoles as Inhibitors of Copper Corrosion, Appl. Sci., 2019, 9, no. 22, 4882. doi: 10.3390/app9224882

17. El-Sayed M. Sherif, R.M. Erasmus and J.D. Comins, Effects of 3-amino-1,2,4-triazole on the inhibition of copper corrosion in acidic chloride solutions, J. Colloid Interface Sci., 2007, 311, no. 1, 144-151. doi: 10.1016/j.jcis.2007.02.064

18. Sudheer and M.A. Quraishi, Electrochemical and theoretical investigation of triazole derivatives on corrosion inhibition behavior of copper in hydrochloric acid medium, Corros. Sci., 2013, 70, 161-169. doi: 10.1016/j.corsci.2013.01.025

19. El-Sayed M. Sherif, R.M. Erasmus and J.D. Comins, Corrosion of copper in aerated acidic pickling solutions and its inhibition by 3-amino-1,2,4-triazole-5-thiol, J. Colloid Interface Sci., 2007, 306, no. 1, 96-104. doi: 10.1016/j.jcis.2006.10.029

20. Y. Tang, Y. Chen, W. Yang, X. Yin, Y. Liu and J. Wang, 3,5-Bis(2-thienyl)-4-amino1,2,4-triazole as a corrosion inhibitor for copper in acidic medi, Anti-Corros. Methods Mater., 2010, 57, no. 5, 227-233. doi: 10.1108/00035591011075850

21. A. Zarrouk, H. Zarrok, R. Salghi, B. Hammouti, R. Touir, I. Warad, F. Bentiss, H. Abou El Makarim and N. Benchat, Quantum chemical study of some triazoles as inhibitors of corrosion of copper in acid media, Res. Chem. Intermed., 2013, 39, 12791289. doi: $10.1007 / \mathrm{s} 11164-012-0684-9$

22. D.S. Shevtsov, Kh.S. Shikhaliev, E.S. Komarova, A.A. Kruzhilin, G.O. Kipriyanova, A.Yu. Potapov, I.D. Zartsyn, O.A. Kozaderov, Ch. Prabhakar and A. Tripathi, Inhibition of Copper Corrosion with N-Arylaminotriazoles in Aqueous Chloride Solutions and in Air, Russ. J. Appl. Chem., 2020, 93, 1152-1159. doi: 10.1134/S1070427220080078

23. D.Q. Zhang, L. Gao and G.D. Zhou, Inhibition of copper corrosion in aerated hydrochloric acid solution by heterocyclic compounds containing a mercapto group, Corros. Sci., 2004, 46, no. 12, 3031-3040. doi: 10.1016/j.corsci.2004.04.012

24. N.K. Allam, A.A. Nazeer and E.A. Ashour, A review of the effects of benzotriazole on the corrosion of copper and copper alloys in clean and polluted environments, J. Appl. Electrochem., 2009, 39, 961-969. doi: 10.1007/s10800-009-9779-4

25. M. Finšgar and I. Milošev, Inhibition of copper corrosion by 1,2,3-benzotriazole: A review, Corros. Sci., 2010, 52, no. 9, 2737-2749. doi: 10.1016/j.corsci.2010.05.002

26. J.M. Bastidas, P. Pinilla, J.L. Polo and E. Cano, Adsorption of Benzotriazole on Copper Electrode Surfaces in Citric Acid Media, Corrosion, 2002, 58, no. 11, 922-931. doi: $\underline{10.5006 / 1.3280782}$

27. E. Cano, P. Pinilla, J.L. Polo and J.M. Bastidas, Copper corrosion inhibition by fast green, fuchsin acid and basic compounds in citric acid solution, Mater. Corros., 2003, 54, no. 4, 222-228. doi: $\underline{10.1002 / \operatorname{maco} .200390050}$ 
28. R. He, Z. Liu and N. Gu, Corrosion inhibition effect of PASP and Sulfuric acid high cerium on copper in Citric Acid, Adv. Mater. Res., 2013, 681, 3-6. doi: 10.4028/www.scientific.net/AMR.681.3

29. V.V. Chugunov, M.I. Bazanov, T.G. Komarova, N.V. Chikunkova and V.V. Chernikov, Specificity of the corrosive behavior of copper, brass and steel in a citric acid solution with various inhibitors, Izvestiya Vysshikh Uchebnykh Zavedenii, Seriya Khimiya $i$ Khimicheskaya Tekhnologiya, 2011, 54, no. 12, 54-57 (in Russian).

30. Ya. Avdeev, M. Tyurina, V. Rabinkov and A. Luchkin, Inhibitive Protection of LowCarbon Steel in Citric Acid Solutions, MATEC Web Conf., RSP 2017 - XXVI R-S-P Seminar 2017 Theoretical Foundation of Civil Engineering, 2017, 117, 8. doi: 10.1051/matecconf/201711700143

31. Ya.G. Avdeev, K.L. Anfilov, E.P. Rukhlenko and Yu.I. Kuznetsov, Inhibitory protection of copper in acetic acid solutions, Int. J. Corros. Scale Inhib., 2021, 10, no. 1, 302-313. doi: 10.17675/2305-6894-2020-10-1-17

32. I.A. Molodov and V.V. Losev, Regularities of the formation of low-valence intermediate particles during the staged electrode process of metal discharge-ionization, Electrochemistry, 7, Moscow, VINITI, 1971, 65-113 (in Russian).

33. Ya.G. Avdeev and N.I. Podobaev, Inhibition by acetylenic alcohols of the cathodic reaction on iron in hydrochloric acid in the presence of oxidants, Korroz.: Mater., Zashch. (Corrosion: materials, protection), 2004, 40, 11-18 (in Russian).

34. Yu.V. Pleskov and V.Yu. Filinovskiy, Rotating disc electrode, Moscow, Nauka, 1972, 344 (in Russian).

35. Ya.G. Avdeev, Protection of metals in phosphoric acid solutions by corrosion inhibitors. A review, Int. J. Corros. Scale Inhib., 2019, 8, no. 4, 760-798. doi: 10.17675/23056894-2019-8-4-1

36. Ya.G. Avdeev, O.A. Kireeva, D.S. Kuznetsov and Yu.I. Kuznetsov, The Influence of Hexamethylenetetramine on the Corrosion Inhibition of Low Carbon Steel in Mixtures of Sulfurous and Phosphorus Acids Containing Fe(III) by IFKhAN-92 and KNCS Composition, Prot. Met. Phys. Chem. Surf., 2018, 54, no. 7, 1298-1304. doi: 10.1134/S2070205118070055

37. Ya.G. Avdeev and Yu.I. Kuznetsov, Inhibitory protection of steels from hightemperature corrosion in acid solutions. A review. Part 3, Int. J. Corros. Scale Inhib., 2020, 9, no. 4, 1194-1236. doi: 10.17675/2305-6894-2020-9-4-3 